\title{
The Effects of Campus Bump on Drivers' Fixation Dispersion and Speed Reduction
}

\author{
Qian Xu, ${ }^{1}$ Fei Shao, ${ }^{1}$ Tangyi Guo, ${ }^{2}$ and Linfeng Gong ${ }^{3}$ \\ ${ }^{1}$ College of Field Engineering, PLA University of Science \& Technology, Nanjing 210007, China \\ ${ }^{2}$ School of Automation, Nanjing University of Science \& Technology, Nanjing 210094, China \\ ${ }^{3}$ Department of Civil and Environmental Engineering, The University of North Carolina at Charlotte, Charlotte, \\ NC 28223-0001, USA
}

Correspondence should be addressed to Fei Shao; shaofeiriver@163.com

Received 22 January 2015; Accepted 4 April 2015

Academic Editor: Wei (David) Fan

Copyright (C) 2015 Qian Xu et al. This is an open access article distributed under the Creative Commons Attribution License, which permits unrestricted use, distribution, and reproduction in any medium, provided the original work is properly cited.

To evaluate the effects of campus speed bumps on drivers' speed and fixation distribution, a quasinaturalistic driving test was conducted on a Chinese campus. Seven randomly selected drivers, wearing the Dikablis eye tracking devices, were required to drive an OPEL SUV passing the speed bumps. The area close to the bump was divided into ten subsegments ( $15 \mathrm{~m}$ for each one). The degree of fixation dispersion within each subsegment was defined as the distance from each subcenter to the whole fixation center. All traffic data were recorded using mounted camera, and the trajectories were extracted in Matlab. The speed and trajectory data was divided into two groups: the before group for bump-free case and the after group for a $5 \mathrm{~cm}$ bump case. The observational before-after analysis shows statistical significance between the two cases. The individual vehicular speed analysis reveals that bump reduces nearly $60 \%$ of vehicles' speeds to a certain extent within the distance from $30 \mathrm{~m}$ upstream to $15 \mathrm{~m}$ downstream. The drivers' fixation points begin to disperse 30-45 m before they see the bump, and it falls back to normal level 15-30 $\mathrm{m}$ downstream of the bump. These findings will help engineers install speed bumps at the most appropriate locations.

\section{Introduction}

On campuses, where a large number of vulnerable road users are expected, the safety situation is not better than that on urban roads or highways. Vulnerable road users, like pedestrians and cyclists, often suffer more serious consequences than automobile drivers do $[1,2]$. Therefore, it is necessary to control the vehicle speed on campuses within a safety level to lower the risk of vulnerability [3]. Among all the possible traffic calming measures, speed bumps are commonly perceived as an effective method in reducing traffic speed for their easy installation and low cost.

Generally, three kinds of vertical raisings of road pavement, namely, speed bumps, speed humps, and speed lumps (cushion), are commonly used as a cost-efficient option to control speed not only on streets, but also on campus roads $[3,4]$. Since the 1970s, when the raisings of road pavement became popular, many studies have focused on evaluating the impacts of these devices. The most important thing is to determine whether the safety situation of the target road segment will be improved after the installation of traffic calming devices. And the most frequent indicators adopted by researchers are speed related indexes, such as the changes in the 85 th percentile speed $\left(V_{85}\right)$, the mean speed $(\bar{v})$, and the percentage of drivers exceeding the speed limit $(p)$. For instance, Layfield and Parry [5] conducted a before-after analysis to assess the effect of speed cushions on vehicle speeds on 34 local highways. They found that the mean and 85th percentile vehicle speeds both at and between cushions have been reduced by an average of about 13 and $10 \mathrm{mph}$, respectively. In 1997, Fife Council installed a traffic calming scheme on South Park Road, Glenrothes, consisting of 3 " $H$ " humps and 4 " $S$ " humps [6]. The results indicated that the 85 th percentile speeds between the humps were reduced by about $7 \mathrm{mph}$ to about $29.5 \mathrm{mph}$. Similar conclusions could also be found in [7-9]. However, Pau concluded that although 
speed bumps seem to affect drivers' behavior to some extent, their effectiveness as speed reducing devices is quite far from optimal [4].

It is also essential to figure out the spatial effectiveness of traffic calming devices, that is, over what distance upstream and downstream of the traffic calming devices drivers' speed will be reduced. For example, if the spatial influence region of a speed bump was clear, then engineers will find it easier to determine the proper location of speed bumps as well as the number of them for achieving a speed reduction over a road segment. Benekohal et al. studied the effectiveness of the speed photo enforcement (SPE) devices at the point that it stationed and a location 1.5 mile downstream the SPE devices [10]. Their research showed a mixed spatial effect for SPE: at the downstream location, the speed reduction for cars was not significant, while it varied from 0.9 to $2.5 \mathrm{mph}$ for heavy vehicles. Pau and Angius proposed a study of the effectiveness of 23 speed bumps in the city of Cagliari [4]. Speeds measured at speed bump locations, at the crosswalks protected by the devices and at sections of the streets where bumps are installed but far from them (the term "far" means a distance of at least $100 \mathrm{~m}$ from the device), were compared. The statistical analysis revealed that, in the space between the bumps and the crosswalks (20-25 m), there was no significant change in speed. Furthermore, there are also no differences in the speed recorded at speed bump locations and at sections of the same street with $100 \mathrm{~m}$ observation distance.

Based on those studies mentioned above, we cannot draw firm conclusions about the spatial effectiveness of the devices because of the following. (1) Vehicle speeds were usually recorded at few spots, such as at 2 or 3 points [4, $10,11]$ along the road segment; therefore, we have limited information of how vehicle speeds change along the entire road segment. (2) Speed indicators used in these researches are collective indexes; some bias may be induced due to loss of information of the data aggregation process, that is, the socalled ecological fallacy.

To address the first issue, speed profiles were proposed by researchers to delineate how vehicle speeds change along with the target road segment $[12,13]$. For example, Liu et al. developed speed profiles in the vicinity of pedestrian crosswalks to evaluate the impacts of transverse rumble strips on vehicle speeds [14]. In another research, Santiago-Chaparro et al. used speed profiles to evaluate the spatial effectiveness of speed feedback signs [15]. There is a slight difference between these two studies; that is, the speeds used to develop speed profiles in the former study are aggregated indicators, that is, $V_{85}$ and $\bar{v}$, while the latter collected the speed profiles of each individual vehicle. Besides, it is recommended that vehicle trajectories could also be used as a nonaggregate index to describe driver behaviors; see [16]. Thus, it can be concluded that the combination of collective indictors $\left(V_{85}\right.$, $\bar{v}$, and $p$ ) and individual indicators (individual vehicle speed profiles and trajectories) might help researchers to get a better understanding about driver behavior while encountering traffic calming devices.

The primary of this study is to evaluate whether vehicle speed is reduced to a compatible level, and if yes, what the spatial effectiveness of campus bumps is, and how drivers' eyes behave corresponding to the presence of bump. A "before and after" method was introduced at a defined special campus road point. And a new method based on computer vision techniques was proposed to extract trajectories and speed profiles of each vehicle passing the research area. At the same time, traditional speed indicators were calculated as well. The effectiveness of the speed bumps on Chinese campus was evaluated by using both aggregate analysis and nonaggregate analysis. Furthermore, an attempt to determine the spatial and physical effectiveness of the speed bumps was also presented.

\section{Data Collection}

2.1. Testing Scenario. In this study, the observations were conducted on weekdays during morning peak hours using a video camera mounted on the top of a five-floor building near the \# 1 road, which is a commuting road on the campus of the Nanjing University of Science and Technology. The width of the roadway is 8 meters between both vertical curbs. The camera covers a range of more than 150 meters along the road segment. Unlike the traditional data collection method (i.e., radar gun) the mounted camera has no influence on drivers as it is invisible while driving.

The first observation was made to obtain the "bumpfree" data when there was no bump installed initially. And it was noted as a bump-free case. The second observation was made after a $5 \mathrm{~cm}$ speed bump installed which is noted as a bump case. These two observations were both conducted at weekday's peak hours from 7:00 to 9:00 am in good weather conditions. Both cases covered more than four-hour video in total. The bump is $5.4 \mathrm{~m}$ long, leaving a $1.3 \mathrm{~m}$ space between the bump end and the road curb on both ends of the bump. During the observations, the major traffic direction on this road is from north to south. We defined the north bound $(0,-35 \mathrm{~m})$ as the upstream direction and the south bound $(0,35 \mathrm{~m})$ as downstream. The testing scenario is displayed in Figure 1. Within the camera's coverage, seven cross-sections $\left(N_{3}, N_{2}, N_{1}\right.$, BUMP, $S_{1}, S_{2}$, and $\left.S_{3}\right)$ were marked, with an interval of $10 \mathrm{~m}$ between each cross-section.

2.2. Camera Calibration. Video based data collection is easy, quick, and efficient. Moreover, it avoids the negative impacts of the presence of speed acquisition devices like radar guns [17]. The speed attributes obtained from video are closer to reality. Nevertheless, extracting useful information from recorded video files is important but time-consuming. Firstly, the single gauss model was used to transform the world coordinate and the camera coordinate to the image plane or pixel coordinate. To reduce the error during the coordinate transformation process, we chose 23 points for calibration and 7 points for testing. All the 30 points are obvious in the real world and easy to be recognized in the image. The distribution of the 30 points is shown in Figure 2.

The camera calibration results are listed in Table 1 . In the world coordinate (real world), the $x$-axis and $y$-axis errors range from 0.04 to $0.24 \mathrm{~m}$ (mean value: 0.14 ) and 0.01 to 
TABLE 1: Camera calibration results and the errors.

\begin{tabular}{|c|c|c|c|c|c|c|c|c|}
\hline \multirow[b]{2}{*}{ Testing points } & \multicolumn{2}{|c|}{ Image plane (pixel) } & \multicolumn{6}{|c|}{ World coordinate $(\mathrm{m})$} \\
\hline & Horizontal axis & Vertical axis & $\begin{array}{c}X \text {-axis } \\
\text { (observed) }\end{array}$ & $\begin{array}{c}X \text {-axis } \\
\text { (computed) }\end{array}$ & Error & $\begin{array}{c}Y \text {-axis } \\
\text { (observed) }\end{array}$ & $\begin{array}{c}Y \text {-axis } \\
\text { (computed) }\end{array}$ & Error \\
\hline$P_{1}$ & 2030.8 & 1231.3 & 2.81 & 2.09 & 0.09 & -13.18 & -13.32 & 0.14 \\
\hline$P_{2}$ & 2394.3 & 1051.8 & 2.25 & 2.06 & 0.20 & -25.17 & -25.13 & 0.04 \\
\hline$P_{3}$ & 1991.8 & 1966.3 & 13.06 & 13.27 & 0.21 & -16.49 & -16.38 & 0.11 \\
\hline$P_{4}$ & 1627.3 & 1700.3 & 8.1 & 8.27 & 0.17 & 5.34 & 5.33 & 0.01 \\
\hline$P_{5}$ & 1524.3 & 1695.3 & 7.38 & 7.61 & 0.24 & 14.36 & 14.20 & 0.16 \\
\hline$P_{6}$ & 1445.8 & 1523.3 & 2.32 & 2.28 & 0.04 & 26.59 & 26.83 & 0.25 \\
\hline$P_{7}$ & 1557.8 & 1466.8 & 2.25 & 2.21 & 0.04 & 15.43 & 15.39 & 0.04 \\
\hline
\end{tabular}

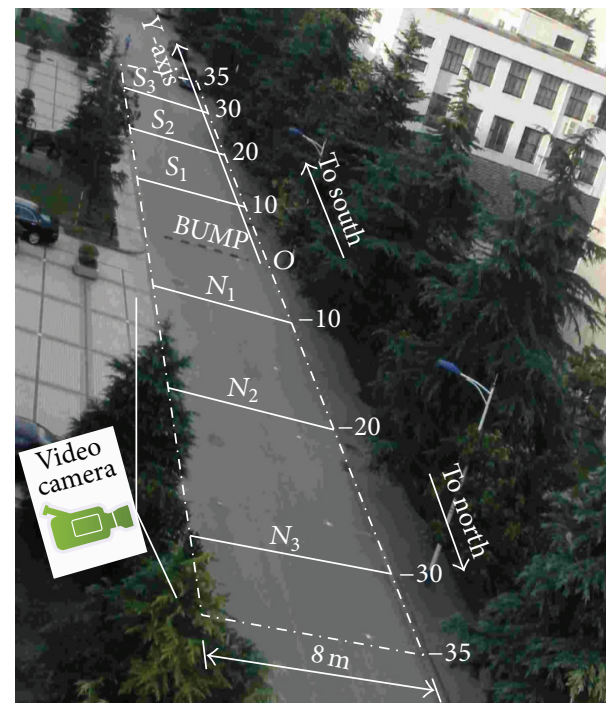

Selected cross-sections

Defined research area

FIGURE 1: Testing scenario.

$0.25 \mathrm{~m}$ (mean value: 0.11 ), respectively. The errors are within the allowable limits and the results are acceptable.

\subsection{Trajectory Extraction and Speed Calculation. In MAT-}

$\mathrm{LAB}$, every vehicle's trajectory, together with the speed on any point of the trajectory, was extracted from the video recorded in the two observations. Due to the existence of calibration error and background disturbance, there were noises on the trajectories, as shown in Figure 3(a). B-spline curvefitting technology was introduced to smooth the original trajectories. The trajectories after smoothing were presented in Figure 3(b).

After obtaining the trajectories, the individual speed data of each vehicle that passes the defined cross-section were calculated. We defined the point speed of each crosssection $v_{i}$ as the mean speed of a small enough distance from point A to point $\mathrm{B}$ which locate beside the $i$ th crosssection symmetrically. We can get the trajectory distance $S_{\mathrm{AB}}$

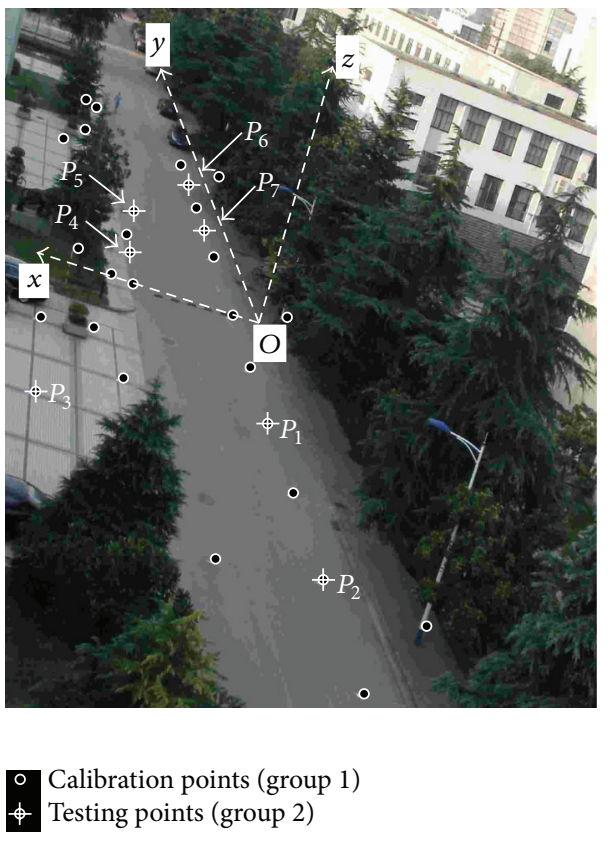

FIGURE 2: Distribution of calibration and testing points.

and travel time $t_{\mathrm{AB}}$ according to the recorded video. So the calculation equation is

$$
v_{i}=\frac{S_{\mathrm{AB}}}{t_{\mathrm{AB}}}=\frac{S_{\mathrm{AB}}}{N_{\mathrm{AB}} / 25},
$$

where $N_{\mathrm{AB}}$ represent the number of frames traveling from $\mathrm{A}$ to $\mathrm{B}$. As the camera takes pictures, 25 frames per second in this study, the travel time between two successive frames is $1 / 25$ seconds, and the $t_{\mathrm{AB}}$ is equal to $N_{\mathrm{AB}} / 25$.

\section{Effects on Speed}

The effects of campus bumps on speed can be assessed using two kinds of speed indicators. The first one is the aggregate speed-based measures, including the difference between operating speeds, $\Delta V_{85}$, and the difference between average speeds, $\Delta V$. These methods draw aggregate sample data from independent population that follow a normal 


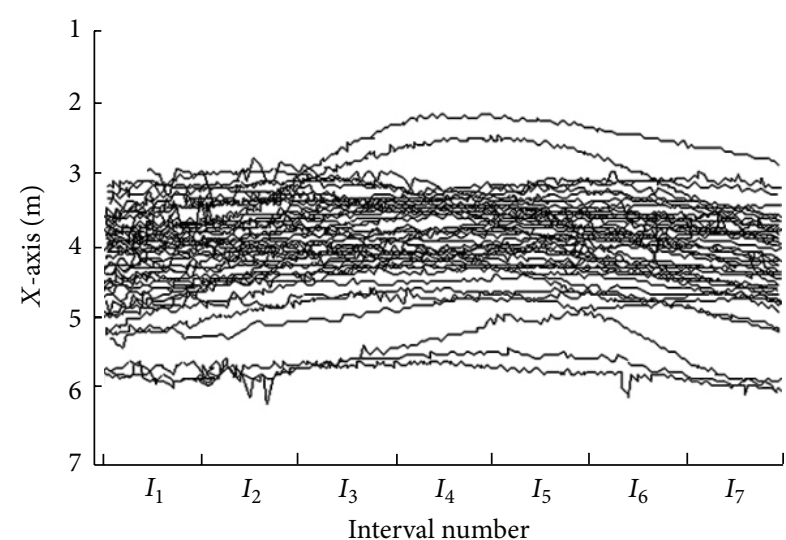

(a) Original vehicle trajectories

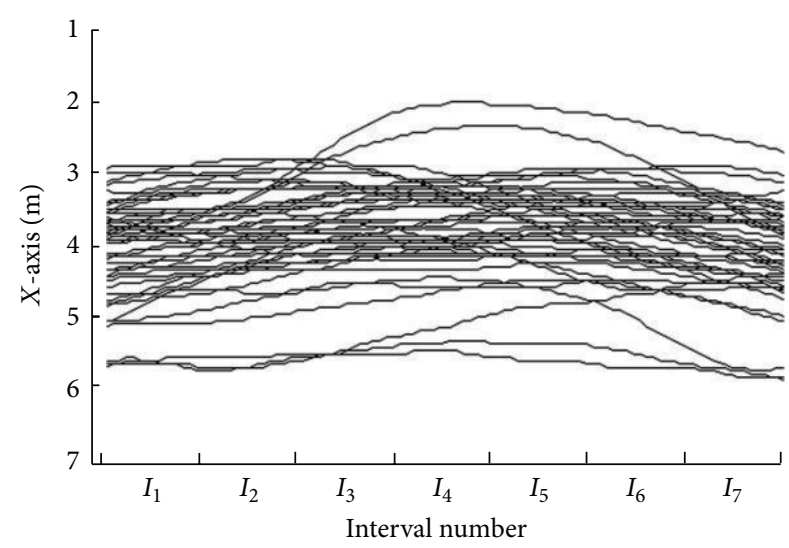

(b) Smoothed vehicle trajectories

FIgURE 3: Vehicle movement trajectories before and after being smoothed.
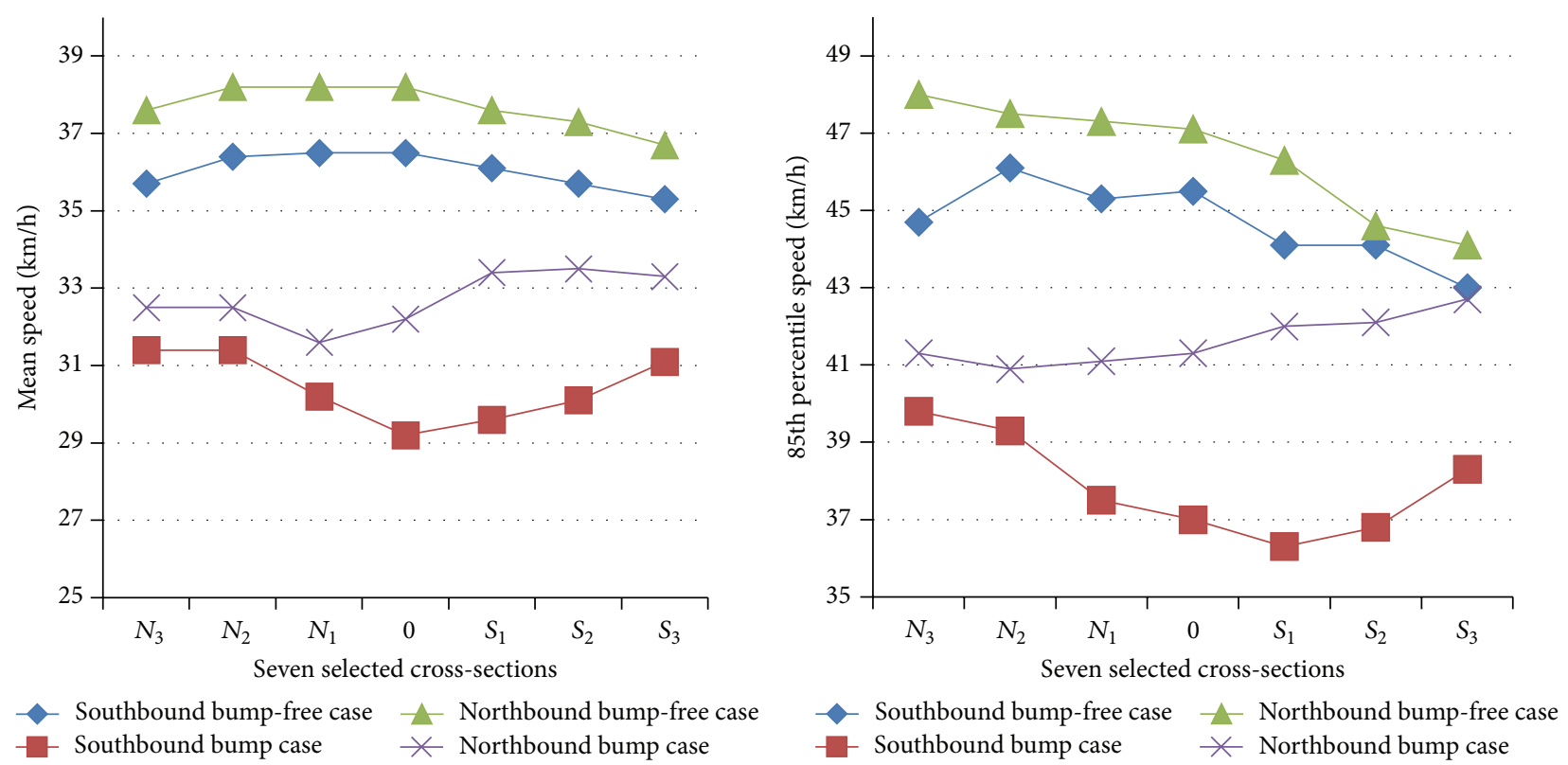

Figure 4: Aggregate speed indicators.

distribution. The other category is the disaggregate measures using individual speed data. 85 MSR (the 85th percentile maximum speed reduction) introduced by McFadden and $\Delta 85 \mathrm{~V}$ developed by Misaghi is of this category $[18,19]$. Their remarkable finding is that operating speed-based measures overestimate safety performance compared with the disaggregate ones. In this study, we use both the aggregate and disaggregate measures to evaluate the spatial effectiveness of campus bump.

3.1. Aggregate Measures Based on $\bar{v}$ and $V_{85}$. Based on the individual speed date, the mean speed $(\bar{v})$ and the 85 th percentile speed $\left(V_{85}\right)$ of bump-free case and bump case were calculated and presented in Figure 4. The travel directions were distinguished as well. Comparing these two cases, the figure clearly shows that the mean speed and the 85th percentile speed in the bump case were lower than that in the bump-free case, in both directions.

The $t$-test indicates that the reduction in the mean speed and the 85th percentile speed is statistically significant. The results are summarized in Table 2.

By comparing the mean speed $(\bar{v})$ and the 85 th percentile speed $\left(V_{85}\right)$, it could be concluded that a speed bump reduces drivers' speeds while passing the target road segment. But how long in distance does the bump take effect on speed reduction? In this study, ANOVA (analysis of variance) is applied to evaluate the spatial effectiveness of the $5 \mathrm{~cm}$ bump on speed decreasing. 
TABLE 2: Summary statistics of aggregate indicators at each cross-section.

\begin{tabular}{|c|c|c|c|c|c|c|c|c|c|}
\hline Interv & mber & $N_{3}$ & $\mathrm{~N}_{2}$ & $N_{1}$ & 0 & $S_{1}$ & $S_{2}$ & $S_{3}$ & $t$-test $(p<0.05)$ \\
\hline \multirow{4}{*}{ Southbound } & $\bar{v}^{1}(\mathrm{~km} / \mathrm{h})$ & 35.7 & 36.4 & 36.5 & 36.5 & 36.1 & 35.7 & 35.3 & \multirow{2}{*}{ Yes } \\
\hline & $\bar{v}^{2}(\mathrm{~km} / \mathrm{h})$ & 31.4 & 31.4 & 30.2 & 29.2 & 29.6 & 30.1 & 31.1 & \\
\hline & $V_{85}{ }^{1}(\mathrm{~km} / \mathrm{h})$ & 44.7 & 46.1 & 45.3 & 45.5 & 44.1 & 44.1 & 43.0 & \multirow{2}{*}{ Yes } \\
\hline & $V_{85}^{2}(\mathrm{~km} / \mathrm{h})$ & 39.8 & 39.3 & 37.5 & 37.0 & 36.3 & 36.8 & 38.3 & \\
\hline \multirow{4}{*}{ Northbound } & $\bar{v}^{1}(\mathrm{~km} / \mathrm{h})$ & 37.6 & 38.2 & 38.2 & 38.2 & 37.6 & 37.3 & 36.7 & \multirow{2}{*}{ Yes } \\
\hline & $\bar{v}^{2}(\mathrm{~km} / \mathrm{h})$ & 32.5 & 32.5 & 31.6 & 32.2 & 33.4 & 33.5 & 33.3 & \\
\hline & $V_{85}{ }^{1}(\mathrm{~km} / \mathrm{h})$ & 48.0 & 47.5 & 47.3 & 47.1 & 46.3 & 44.6 & 44.1 & \multirow{2}{*}{ Yes } \\
\hline & $V_{85}^{2}(\mathrm{~km} / \mathrm{h})$ & 41.3 & 40.9 & 41.1 & 41.3 & 42.0 & 42.1 & 42.7 & \\
\hline
\end{tabular}

Data collected in the bump-free case.

${ }^{2}$ Data collected in the bump case.

3.2. Disaggregate Measures Based on IVSR and Trajectories. In reality, the speed distribution is not necessarily distributed normally, as assumed by $\Delta V_{85}$ or by $\bar{v}$. Speed varies from one driver to another due to their divergent personal characteristics. And vehicle attributes have noticeable effects on operating speed $[20,21]$. Therefore, more individual driver information needs to be exploited to get concrete conclusions about the spatial effect of the speed bump.

In this study, the individual vehicle speed reduction (IVSR) was proposed to estimate how much the speed is decreased and how many drivers do yield to the bump.

Considering the point speed at bump location as a benchmark, the individual vehicle speed reduction of other cross-section $\mathrm{IVSR}_{i}$ can be calculated with the following equation:

$$
\mathrm{IVSR}_{i}=v_{i}-v_{\text {bump }}
$$

where $v_{i}$ and $v_{\text {bump }}$ represent the point speed at selected crosssection and bump location.

In Figure 5, speeds that decrease more than $5 \mathrm{~km} / \mathrm{h}$, between 2 and $5 \mathrm{~km} / \mathrm{h}$, and less than $2 \mathrm{~km} / \mathrm{h}$ are categorized into significant (red), moderate (blue), and negligible (green) effect group, respectively. Among the 77 vehicles driving from north to south, $21(27.27 \%)$ decreased their speed over $5 \mathrm{~km} / \mathrm{h}, 24(31.17 \%)$ decreased their speed from 2 to $5 \mathrm{~km} / \mathrm{h}$, $27(35.06 \%)$ decreased their speed less than $2 \mathrm{~km} / \mathrm{h}$, and 5 (6.49\%) even increased their speed more than $5 \mathrm{~km} / \mathrm{h}$ while crossing the bump. The significant and moderate groups accounted for $58.44 \%$. In other words, the bump has effect on nearly $60 \%$ drivers. It is also noted that, in Figure 5 , the red lines fluctuate greatly, up to a maximum of $15 \mathrm{~km} / \mathrm{h}$. It seems that more than half of drivers are willing to slow down. However, they do not know what the advisable speed is. This psychological dilemma may be caused by the lack of speed limit signs. Figure 5 also shows that the significantly or moderately affected drivers decrease their speed and reach minimum value at the bump location and then increase the speed to a certain extent. However, it is not symmetric on the north and south bound. The north bound, also the upstream direction, seems more affected by the bump.

3.3. Drivers' Yielding Behavior Analysis. In order to figure out the speed bump's influence on diver behavior along

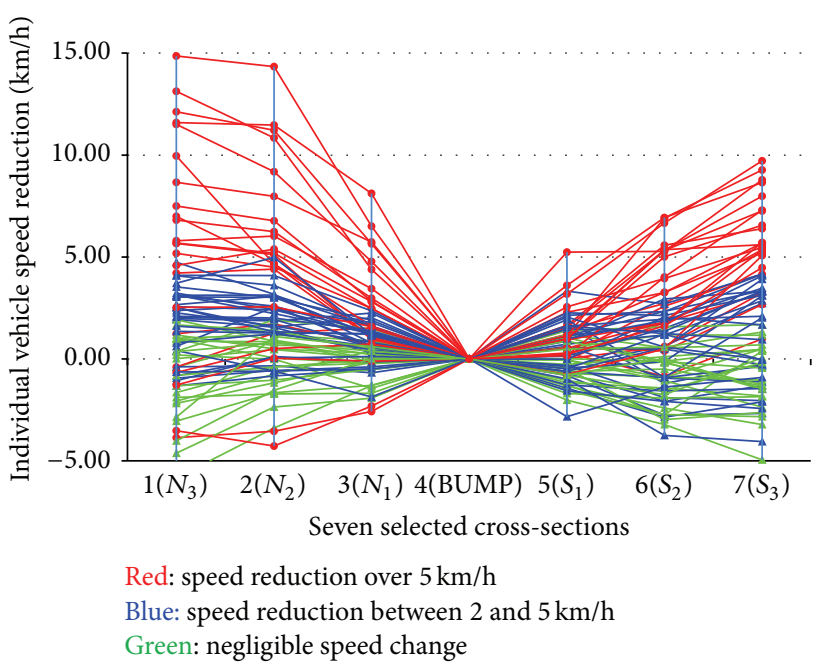

Figure 5: Speed profiles with different reduction degrees $(5 \mathrm{~cm}$ case).

the defined area, that is, the spatial effect of the speed bump, trajectories and speed profiles of each individual vehicle were extracted for an in-depth analysis.

As stated before, a total of 113 trajectories of passing vehicles were extracted in the before group (see Figure 6(a)) and a total of 117 vehicle trajectories were extracted in the after group (see Figure 6(b)). Bear in mind that the speed bump was installed in the center of the interval $I_{4}$ and the space between the endpoint of the speed bump and the edge of the road was $1.3 \mathrm{~m}$.

As shown in Figure 6, an interesting phenomenon could be observed: most vehicle trajectories were straight when there was no speed bump deployed at the designated road segment and only a few drivers changed their direction while passing the defined road segment. However, only about 60 percent of vehicle trajectories are straight lines when a $5 \mathrm{~cm}$ high speed bump was installed on the road and the other 40 percent of vehicles changed their directions when passing the designated road segment after a $5 \mathrm{~cm}$ high speed bump was deployed. This conclusion was quite intuitive because drivers would change their directions to avoid hitting on the speed 
TABLE 3: Analysis of variance (ANOVA) for nonbump and $5 \mathrm{~cm}$ bump cases.

\begin{tabular}{|c|c|c|c|c|c|c|}
\hline \multicolumn{2}{|c|}{ Cross-sections } & Sum of squares & $\mathrm{df}$ & Mean square & $F$ & Sig. $(p)$ \\
\hline \multirow{2}{*}{$N_{3}$} & Between groups & 217.182 & 1 & 217.182 & \multirow{2}{*}{3.736} & \multirow{2}{*}{0.055} \\
\hline & Within groups & 13021.186 & 224 & 58.130 & & \\
\hline \multirow{2}{*}{$N_{2}$} & Between groups & 415.786 & 1 & 415.786 & \multirow{2}{*}{6.737} & \multirow{2}{*}{0.010} \\
\hline & Within groups & 13825.261 & 224 & 61.720 & & \\
\hline \multirow{2}{*}{$N_{1}$} & Between groups & 481.985 & 1 & 481.985 & \multirow{2}{*}{7.393} & \multirow{2}{*}{0.007} \\
\hline & Within groups & 14603.300 & 224 & 65.193 & & \\
\hline \multirow{2}{*}{ Bump } & Between groups & 597.574 & 1 & 597.574 & \multirow{2}{*}{8.689} & \multirow{2}{*}{0.004} \\
\hline & Within groups & 15405.896 & 224 & 68.776 & & \\
\hline \multirow{2}{*}{$S_{1}$} & Between groups & 444.579 & 1 & 444.579 & \multirow{2}{*}{6.910} & \multirow{2}{*}{0.009} \\
\hline & Within groups & 14412.166 & 224 & 64.340 & & \\
\hline \multirow{2}{*}{$S_{2}$} & Between groups & 215.954 & 1 & 215.954 & \multirow{2}{*}{3.342} & \multirow{2}{*}{0.069} \\
\hline & Within groups & 14475.750 & 224 & 64.624 & & \\
\hline \multirow{2}{*}{$S_{3}$} & Between groups & 143.508 & 1 & 143.508 & \multirow{2}{*}{2.304} & \multirow{2}{*}{0.130} \\
\hline & Within groups & 13949.380 & 224 & 62.274 & & \\
\hline
\end{tabular}

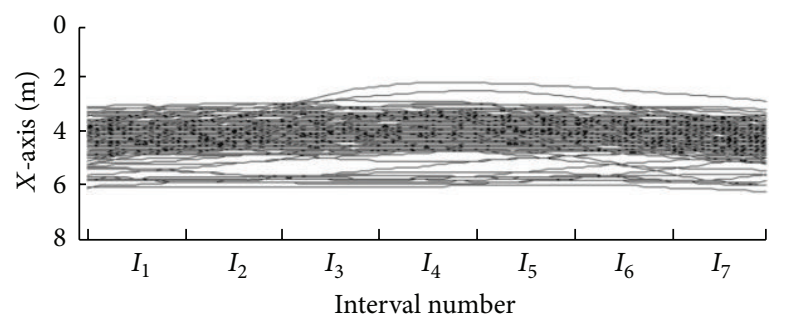

(a) Nonbump case

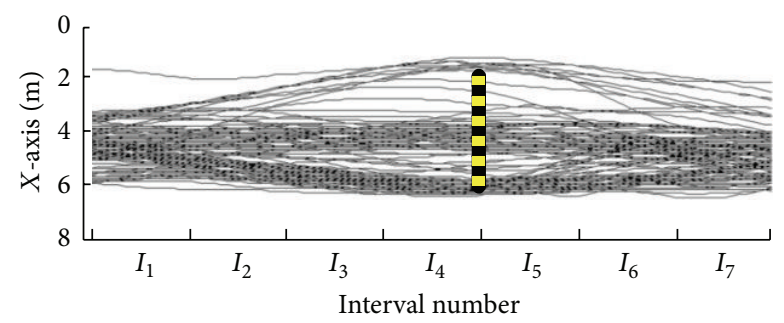

(b) $5 \mathrm{~cm}$ speed bump case

FIGURE 6: Vehicle trajectories of the bump-free case and the $5 \mathrm{~cm}$ bump cases.

bump less dramatically and thus reducing the vibration which may make themselves uncomfortable.

3.4. Analysis of Variance. ANOVA is capable of comparing the statistical significance of the variations observed between the nonbump case and $5 \mathrm{~cm}$ bump case. In this paper, one way ANOVA (also called $F$-test) was performed and the correspondent $P$ values were calculated (Table 3 ). The ANOVA $F$-statistic is a ratio of the between-group variation (MSBG) divided by the within-group variation (MSWG):

$$
F=\frac{\mathrm{MSBG}}{\mathrm{MSWG}} \text {. }
$$

A large $F$ is evidence against $H_{0}\left(H_{0}\right.$ : the means of the two groups are equal) since it indicates that there is more difference between groups than within groups. At a confidence level of $95 \%$, a larger $F$ value and $P \leq 0.05$ indicate statistical significance. On this basis, there is a significant difference on four of the total seven sections $\left(N_{2}, N_{1}\right.$, bump section, and $S_{1}$ ) in Table 3 . It implies that the bump has a longer influencing distance on its upstream and a shorter influencing distance downstream. A linear interpolation to $P$ value shows an approximate significant range from upstream $28.89 \mathrm{~m}$ to downstream $16.83 \mathrm{~m}$. Rounded to $5 \mathrm{~m}$, this range becomes 30 to $15 \mathrm{~m}$. So we can conclude that the $5 \mathrm{~cm}$ bump decreases speed within the range from its upstream $30 \mathrm{~m}$ to downstream $15 \mathrm{~m}$.

\section{Effects on Fixation}

An additional field observation was conducted on the same road to see the drivers' eye movement behaviors. Seven randomly selected drivers, wearing the D-LAB Dikablis eye tracking devices, were asked to drive an OPEL SUV passing the speed bump areas for 10 times. A single fixation point and a cluster of fixation points were shown in Figure 7. The area close to the bump was divided into ten subsegments ( $15 \mathrm{~m}$ for each one), with 5 upstream and 5 downstream. We compared the eye tracking data of each subsegment with the whole $150 \mathrm{~m}$ length segment. There is a fixation center for the whole segment and 10 subfixation centers for the subsegments. In this study, the degree of fixation dispersion (DFD) within each subsegment was defined as the distance from each subcenter to the whole center.

The DFD for each subsegment is listed in Table 4. The paired $t$-test for each driver shows no significant difference between subsegments. However, the changing trend of the seven drivers' averaged DFD value within each subsegment 
TABLE 4: Each driver's DFD values within each subsegment.

\begin{tabular}{lcccccccccc}
\hline Subsegment & U75-60 & U60-45 & U45-30 & U30-15 & U15-0 & D0-15 & D15-30 & D30-45 & D45-60 & D60-75 \\
\hline Driver 1 & 23.44 & 20.04 & 19.22 & 26.38 & 23.06 & 22.76 & 23.23 & 18.76 & 20.76 & 25.10 \\
Driver 2 & 24.44 & 26.57 & 25.11 & 31.16 & 29.06 & 29.34 & 19.39 & 24.77 & 34.15 & 33.29 \\
Driver 3 & 26.00 & 22.78 & 22.23 & 19.35 & 26.44 & 23.15 & 18.15 & 16.62 & 17.96 & 16.84 \\
Driver 4 & 24.90 & 25.44 & 29.62 & 27.56 & 32.44 & 32.49 & 29.53 & 37.36 & 15.79 & 23.73 \\
Driver 5 & 15.85 & 43.26 & 23.62 & 25.20 & 21.67 & 47.81 & 19.78 & 10.88 & N/A & N/A \\
Driver 6 & 18.87 & 23.18 & 35.29 & 26.51 & 31.43 & 38.11 & 33.47 & 35.17 & 37.43 & 35.74 \\
Driver 7 & 21.24 & 12.25 & 19.46 & 40.21 & 26.87 & 23.91 & 21.32 & 19.60 & 20.47 & 18.57 \\
Average & 22.11 & 24.79 & 24.94 & 28.05 & 27.28 & 31.08 & 23.55 & 23.31 & 24.43 & 25.55 \\
\hline
\end{tabular}
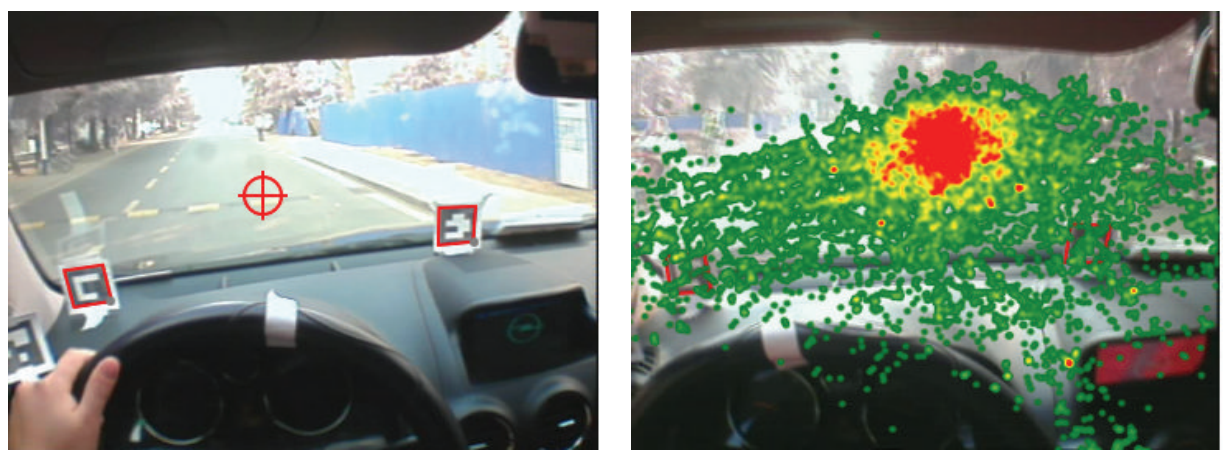

FIgURE 7: A single fixation point and a cluster of fixation points.

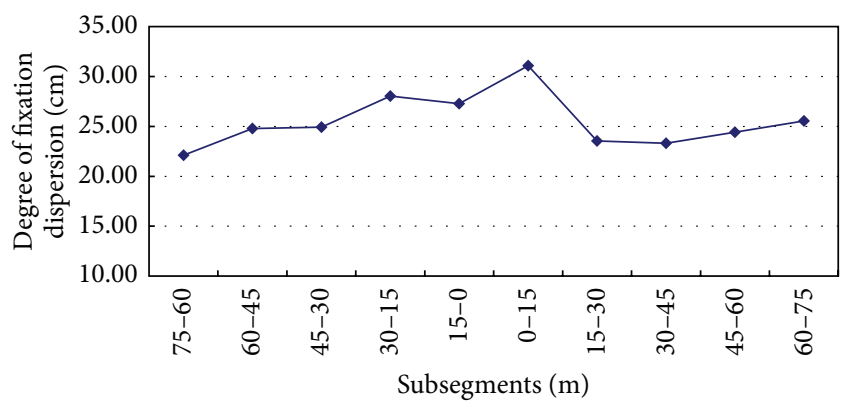

FIgURE 8: The changing trend of drivers' averaged DFD values.

along the coverage area suggests that the speed bump does have some effect on the drivers' eye movement behaviors. From Figure 8, we may draw the conclusion that the drivers fixation points begin to disperse after the drivers see the bump at the third subsegment upstream and the fall back to normal level at the second subsegment downstream. In other words, the bump takes effect on drivers' eye movement from the upstream 30-45 $\mathrm{m}$ to the downstream 15-30 m.

\section{Conclusions}

In this study, the research team evaluated the effectiveness of the speed bump installed on a Chinese campus using conventional aggregate indicators $\left(\bar{v}, V_{85}\right)$ and disaggregate individual vehicle speed reduction (IVSR) indicator as well.
Based on the trajectory analysis, effect evaluation on speed, and fixation distribution, we came to the following conclusions.

Firstly, the bump does have effect on speed reduction and drivers' fixation distribution.

Secondly, based on ANOVA test, the bump has effect on speed decreasing not only at the point of device, but also extends to a certain distance from both sides of the device. This finding contradicts Pau's conclusion that the effectiveness of speed bumps is "punctiform," reducing vehicle speed only at the point of the device. However, the effect on speed behavior in terms of distance and degree is not symmetrical on both sides of the bump. There is a longer influencing distance $(30 \mathrm{~m})$ on its upstream direction and a shorter distance $(15 \mathrm{~m})$ for downstream.

Thirdly, compared with aggregate speed measures $\bar{v}$ and $V_{85}$, the disaggregate indicator, IVSR, is capable of assessing all the individual vehicle's speed behaviors. The analysis based on IVSR revealed that the $5 \mathrm{~cm}$ bump installed on campus decreases nearly $60 \%$ (65 in 113) of vehicles' speeds within the bump's influencing area. Besides, the result of trajectory analysis reveals that about $40 \%$ of drivers will change their directions to reduce the vibration generated by the speed bump.

Last but not the least, the distribution of drivers' fixation points begins to disperse $30-45 \mathrm{~m}$ before they see the bump and then falls back to normal at 15-30 m downstream of the bump. 
The findings in this study demonstrated that driver behavior would be changed with the deployment of a speed bump. However, it should be noted that even though these findings can be considered reasonable, they should be applied carefully since the conclusion was made based on data measured at only one experiment site. More experiment sites are needed for tests in order to draw firm conclusions.

While expanding the study areas to other roadways (urban streets and highways), we should focus on (a) the impacts of bump height on speed decreasing so as to find an optimal height for the deployment; (b) the impacts of speed bumps on drivers' psychology, physiology, and comfort; (c) safety performance for special vehicles (construction vehicles and trucks) and other road users (pedestrians, motorcyclists, electric bicyclists, and bicyclists); (d) the relationship between crashes and the deployment of speed bumps. Currently, task (b) is under way. With the Dikablis eye tracking system and other devices, the data of more subjects' eye movement, physical, and psychological behaviors will be collected.

\section{Conflict of Interests}

The authors declare that there is no conflict of interests regarding the publication of this paper.

\section{Acknowledgments}

This research is financially supported by the National Natural Science Foundation of China (51208261), the Science Foundation of Ministry of Education of China (12YJCZH062), the Fundamental Research Funds for the Central Universities (30920140132033), and the National Basic Research Program of China (2014CB046801 and 2014CB046804). The authors also would like to thank the Department of Transportation at the Nanjing University of Science and Technology for their contribution to the data collection.

\section{References}

[1] S. J. Ashton, Vehicle Design and Pedestrian Injuries: I. Pedestrian Accidents, edited by: A. J. Chapman, F. M. Wade, H. C. Foot, John Wiley \& Sons, New York, NY, USA, 1982.

[2] W. Teichgräber, "The significance of speed for traffic safety," Journal of Traffic Safety, vol. 2, II Quarter, 1983.

[3] B. Antić, D. Pešić, M. Vujanić, and K. Lipovac, "The influence of speed bumps heights to the decrease of the vehicle speedBelgrade experience," Safety Science, vol. 57, pp. 303-312, 2013.

[4] M. Pau and S. Angius, "Do speed bumps really decrease traffic speed? An Italian experience," Accident Analysis \& Prevention, vol. 33, no. 5, pp. 585-597, 2001.

[5] R. E. Layfield and D. I. Parry, "Traffic calming_speed cushion schemes," TRL Report 312, Transport Research Laboratory, Berkshire, UK, 1998.

[6] D. C. Webster and R. E. Layfield, "Traffic calming-sinusoidal, 'H' and 'S' humps,' TRL Report 377, Transport Research Laboratory, Berkshire, UK, 1998.

[7] Bureau of Traffic Management, City of Portland Speed Bump Peer Review, Bureau of Traffic Management, Portland, Ore, USA, 1998.
[8] N. C. Kevin, N. Matthew, and L. N. Nancy, "Developing design standards for speed cushions," Transportation Research Record, no. 2030, pp. 22-28, 2007.

[9] S. M. Casey and A. K. Lund, "The effects of mobile roadside speedometers on traffic speeds," Accident Analysis \& Prevention, vol. 25, no. 5, pp. 627-634, 1993.

[10] R. F. Benekohal, M. V. Chitturi, A. Hajbabaie, M.-H. Wang, and J. C. Medina, "Automated speed photo enforcement effects on speeds in work zones," Transportation Research Record: Journal of the Transportation Research Board, vol. 2055, pp. 11-20, 2008.

[11] C. Johansson, P. Rosander, and L. Leden, "Distance between speed humps and pedestrian crossings: does it matter?" Accident Analysis \& Prevention, vol. 43, no. 5, pp. 1846-1851, 2011.

[12] H. M. Barbosa, M. R. Tight, and A. D. May, "A model of speed profiles for traffic calmed roads," Transportation Research Part A: Policy and Practice, vol. 34, no. 2, pp. 103-123, 2000.

[13] T. M. Ana, A. García, and M. A. Romero, "Speed table evaluation and speed modeling for low-volume crosstown roads," Transportation Research Record Journal of the Transportation Research Board, no. 2203, pp. 85-93, 2011.

[14] P. Liu, J. Huang, W. Wang, and C. C. Xu, "Effects of transverse rumble strips on safety of pedestrian crosswalks on rural roads in China," Accident Analysis and Prevention, vol. 43, no. 6, pp. 1947-1954, 2011.

[15] K. R. Santiago-Chaparro, M. Chitturi, A. Bill, and D. A. Noyce, "Spatial effectiveness of speed feedback signs," Transportation Research Record: Journal of the Transportation Research Board, no. 2281, pp. 8-15, 2012.

[16] A. N. David and V. V. Elango, "Safety evaluation of centerline rumble strips: crash and driver behavior analysis," Transportation Research Record, no. 1862, pp. 44-53, 2004.

[17] P. Misaghi and Y. Hassan, "Modeling operating speed and speed differential on two-lane rural roads," Journal of Transportation Engineering, vol. 131, no. 6, pp. 408-418, 2005.

[18] J. McFadden and L. Elefteriadou, "Evaluating horizontal alignment design consistency of two-lane rural highways: development of new procedure," Transportation Research Record, no. 1737, pp. 9-17, 2000.

[19] P. Misaghi, Modeling operating speed and speed differential for design consistency evaluation [M.S. thesis], Department of Civil and Environmental Engineering, Carleton University, Ottawa, Canada, 2003.

[20] T. Guo, Y. Liu, and J. Lu, "Levels of safety at freeway exits: evaluations on the basis of individual speed difference," Transportation Research Record, no. 2241, pp. 10-18, 2011.

[21] G. Kanellaidis, "Factors affecting drivers' choice of speed on roadway curves," Journal of Safety Research, vol. 26, no. 1, pp. 49-56, 1995. 


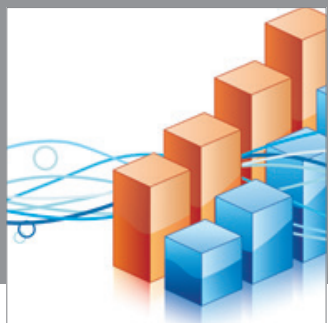

Advances in

Operations Research

mansans

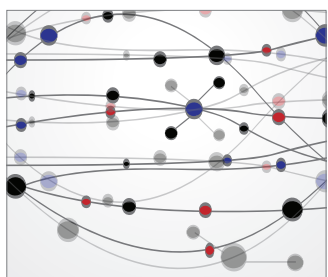

The Scientific World Journal
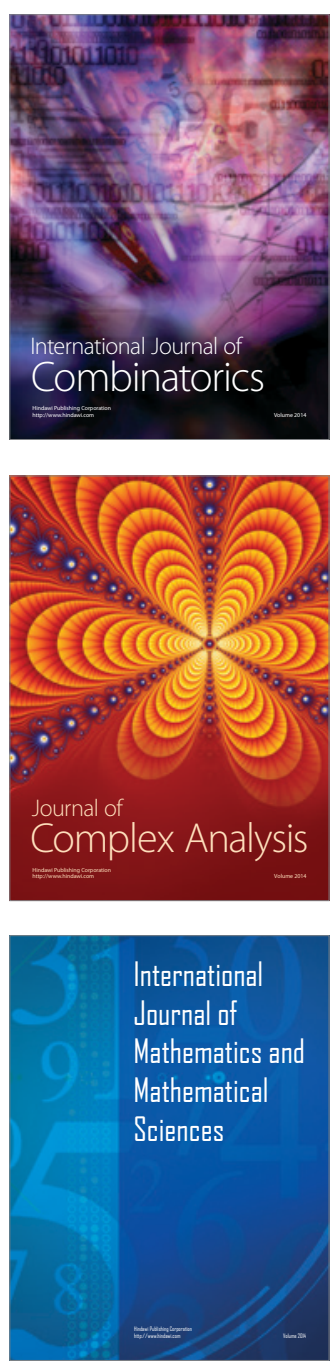
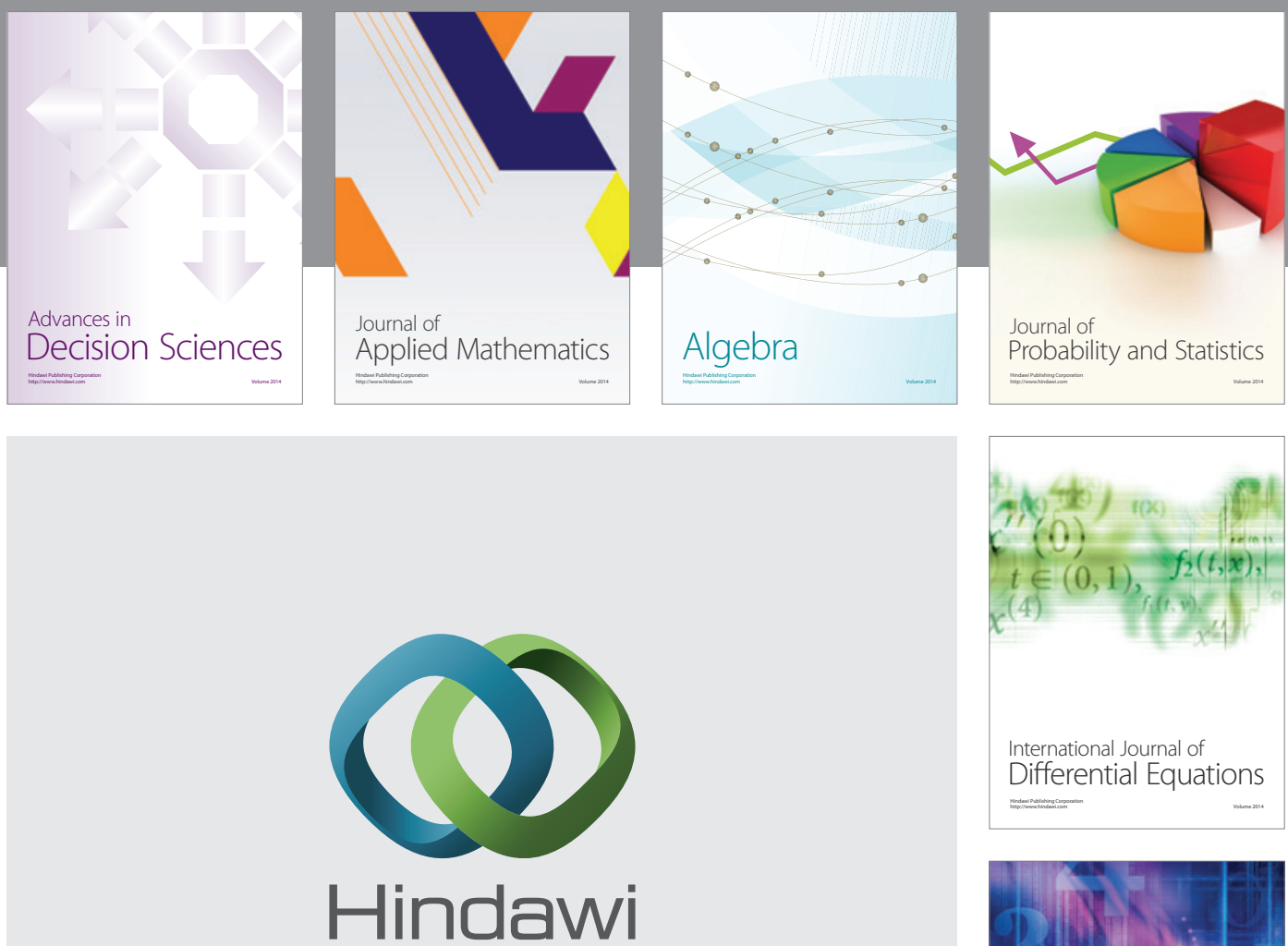

Submit your manuscripts at http://www.hindawi.com
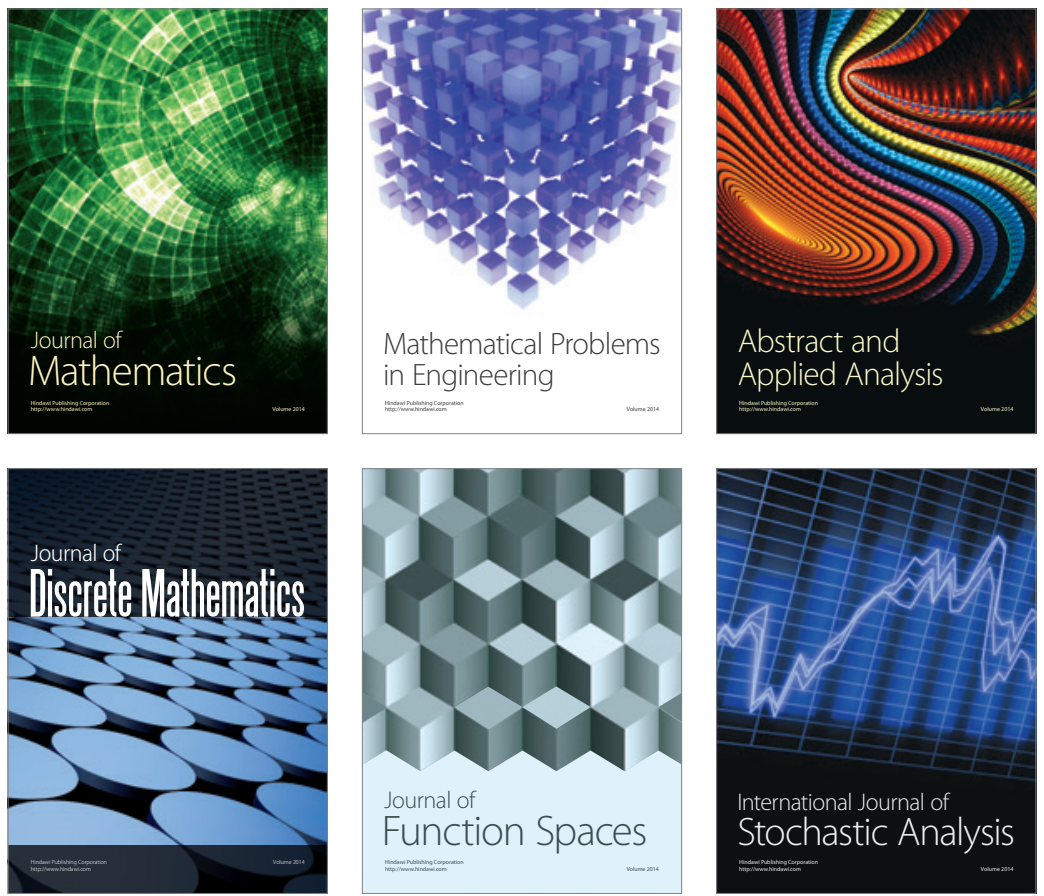

Journal of

Function Spaces

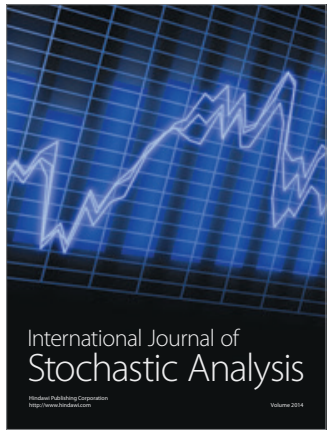

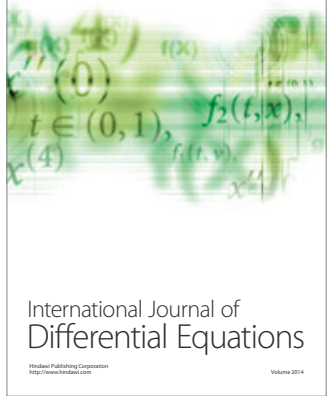
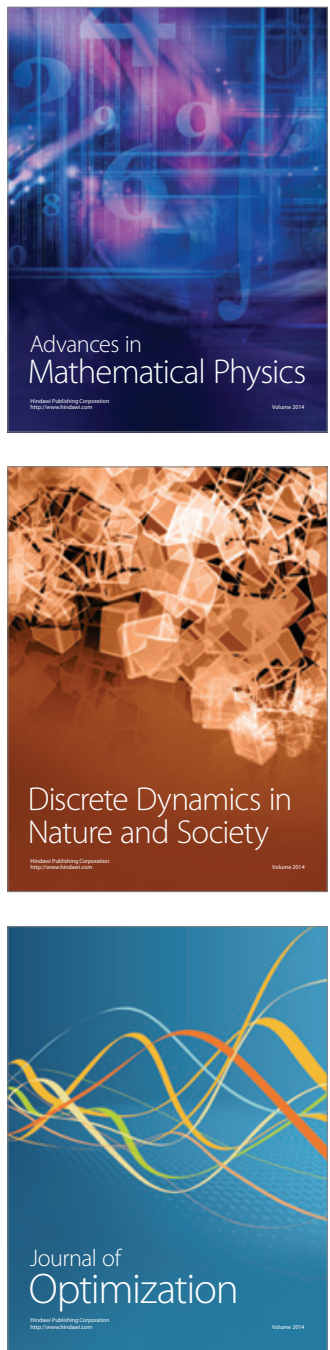